\title{
Desembalando las bibliotecas de la Cuba post-soviética
}

\author{
Unpacking the Libraries of Post-Soviet Cuba \\ Desempacotando as bibliotecas da Cuba pós-soviética
}

\section{Vicky Unruh}

THE UNIVERSITY OF KANSAS, ESTADOS UNIDOS

Profesora Emérita del Departamento de Español y Portugués de la

Universidad de Kansas. Ph. D en Literatura, University of Texas at

Austin. Ha publicado numerosos artículos en revistas especializadas, y los

libros: Telling Ruins in Latin America (Palgrave-MacMillan, 2009, co-

editado con Michael J. Lazzara), Performing Women and Modern Literary

Culture in Latin America (University of Texas Press, 2006), y Latin

American Vanguards: The Art of Contentious Encounters (University

of California Press, 1994). Correo electrónico: kunruh@ku.edu

\footnotetext{
Artículo de reflexión

Publicado originalmente en inglés, "Unpacking the Libraries of Post-Soviet Cuba" en Revista de Estudios Hispánicos, Volume XLVII, Número 2, Junio 2013, 175-198.

Traducción de Raquel Rivas Rojas. Escritora y traductora independiente. Fue profesora titular del Departamento de Lengua y Literatura de la Universidad Simón Bolívar, Caracas, hasta septiembre de 2008. PhD en Estudios Culturales Latinoamericanos del King's College London (2001). Ha publicado: El patio del vecino (Equinoccio, 2013), Narrar en dictadura (El Perro y la Rana, 2011), y Bulla y buchiplumeo. Masificación cultural y recepción letrada en la Venezuela gomecista (La Nave Va, 2002). Vive actualmente en Edimburgo y mantiene dos blogs: Notas para Eliza y Cuentos de la caldera este. Documento accesible en línea desde la siguiente dirección: http://revistas.javeriana.edu.co 


\section{Resumen}

A partir de las renombradas

Palabras a los intelectuales de

1961, pronunciadas por Fidel

Castro en la Biblioteca Nacional

José Martí y la creación de una

red de Bibliotecas estatales, la

biblioteca en Cuba se transformó

en una esfera cultural saturada

de ambigüedad ideológica. En

este contexto, la representación

de la biblioteca en la literatura y

el cine de la época post-soviética

re-escenifica inconclusos

debates entre la libertad de

expresión y el contrato social.

Este análisis demuestra que la reciente producción cultural cubana revigoriza la biblioteca como espacio de negociación ideológica en una época de expectativas precarias y reactiva conversaciones culturales sobre la clase social y la democratización, la propiedad cultural individual o colectiva, y el ideal revolucionario de la inmersión ciudadana en la vida cultural.

Palabras clave: biblioteca; democratización cultural; clase social; propiedad cultural; participación ciudadana; Cuba

\section{Abstract}

Using as a starting point the renowned Palabras a los intelectuales of 1961, expressed by Fidel Castro at the José Martí National Library, and the creation of a network of State Libraries, the library in Cuba became a cultural sphere saturated by ideological ambiguity. Within this context, the representation of the library in the literature and films of the post-Soviet era recreates unfinished debates between freedom of expression and the social contract. This analysis demonstrates that the recent Cuban cultural production invigorates the library as a space for ideological negotiation at a time of precarious expectations and reactive cultural conversations about social class and democratization, the individual or collective cultural property, and the revolutionary ideal of citizenship immersion in cultural life.

Key words: library; cultural democratization; social class; cultural property; citizenship participation; Cuba

\section{Resumo}

A partir das renomadas Palabras a los intelectuales de 1961, pronunciadas por Fidel Castro na Biblioteca Nacional José Martí, e da criação de uma rede de bibliotecas estatais, a biblioteca em Cuba se transformou em uma esfera cultural saturada de ambiguidade ideológica. Neste contexto, a representação da biblioteca na literatura e no cinema da época póssoviética reencena inconclusos debates entre a liberdade de expressão e o contrato social. Esta análise demonstra que a recente produção cultural cubana revigora a biblioteca como espaço de negociação ideológica em uma época de expectativas precárias, e reativa conversas sobre classe social e democratização, propriedade cultural, individual ou coletiva, e o ideal revolucionário da imersão cidadã na vida cultural.

Palavras-chave: biblioteca; democratização cultural; classe social; propriedade cultural; participação cidadã; Cuba 
EN UNA BIBLiOTECA pública atestada y polvorienta, algunos lectores bostezan, limpian sus lentes o pasan las páginas de viejos periódicos a punto de desintegrarse. Esta escena que se repite varias veces en la película Madagascar de Fernando Pérez, proyectada por primera vez en 1994 y producida durante el punto más bajo del llamado Período Especial, muestra una elocuente visión de las estancadas instituciones públicas cubanas. ${ }^{1}$ La imagen es crucial para comprender la representación que esta película propone del estado de desorientación que experimentó en los años noventa del siglo XX la avejentada generación de revolucionarios cubanos, de la cual forma parte la protagonista, Laura, una profesora de Física, y del escaso interés que tienen los hijos de esa generación por los ideales revolucionarios. En franco contraste con esa imagen, la película de Juan Carlos Tabio, Lista de espera (2000), basada en un cuento homónimo de Arturo Arango (1997), imagina la entusiasta restauración de una pequeña biblioteca en un terminal rural en el que los autobuses que llegan tienen apenas unos pocos puestos libres, lo que obliga a los pasajeros a quedarse varados por largo tiempo. Allí, los pasajeros que se quedan ocupan su tiempo ofreciendo las habilidades que tienen para hacer realidad el sueño colectivo de convertir el terminal en la vibrante sede de una comunidad cubana improvisada. Mientras exploran las habitaciones abandonadas del terminal se encuentran con los restos de lo que aspira a ser una biblioteca y comienzan a llenar sus estantes y a catalogar los libros que redescubren en cajas dispersas. Esta breve escena reitera la centralidad de la lectura y de las bibliotecas en el programa de la revolución de 1959, que proponía la democratización de la sociedad y la cultura cubanas a través de una educación que presumiblemente acabaría con las divisiones sociales.

El contraste evidente entre estas dos representaciones de la biblioteca cubana de la era post-soviética como lugar del estancamiento y la pérdida, por un lado, y de la renovación individual y comunitaria, por otro, ejemplifica el lugar relevante que tiene la biblioteca como tropo cultural en el fin de siglo cubano. La biblioteca ya había sido un motivo recurrente en la literatura cubana del siglo XX. Como ejemplo se puede mencionar la atrayente biblioteca interior representada en la novela vanguardista Fardín, de Dulce María Loynaz, escrita en 1935 (que permaneció inédita hasta 1951) o los diversos materiales de lectura que Sofía, el personaje de El siglo de las luces (1962) de Alejo Carpentier, reúne al desmantelar junto a sus hermanos la vieja casa familiar, que data del siglo XVIII, liberándose en ese gesto de la autoridad paterna. Sin embargo, la biblioteca se convirtió en una

1 Los líderes cubanos comenzaron a utilizar la expresión "Período Especial en tiempos de paz" en 1990 . 
esfera cultural con una enorme carga ideológica a partir del conocido discurso Palabras a los intelectuales que Fidel Castro pronunció en junio de 1961 en el Salón de Actos de la Biblioteca Nacional José Martí y con la creación posterior de una red centralizada de bibliotecas públicas en todo el país. Por un lado, la biblioteca constituía un centro simbólico de las campañas de alfabetización que pretendían llegar a todas partes y para la centralidad que tuvo la lectura en el voluntariado revolucionario y la solidaridad imaginada entre cubanos separados por clases sociales. Pero la biblioteca fue también, por otro lado, el lugar performativo fundacional de la tensa relación del Estado con los intelectuales cubanos, condensada en la famosa consigna que Fidel Castro impuso al arte cubano: "[D]entro de la Revolución, todo; contra la Revolución nada" (11). En este contexto, la biblioteca que se representa en la literatura y el cine post-soviéticos ofrece un escenario en el que es posible reformular los debates acerca de la tensión entre la libertad intelectual y el contrato social(ista), la vida privada y la ciudadanía pública.

La primera película cubana que exploró estas tensiones - Memorias del subdesarrollo (1968) de Tomás Gutiérrez Alea- ya ubicaba escenas fundamentales de encuentros entre distintas clases sociales en librerías y en el estudio de la Finca Vigía en la que vivió Ernest Hemingway. ${ }^{2}$ Estos escenarios visibilizan la política cultural que contextualiza la ruptura entre Sergio, el intelectual burgués, y su joven amante, Elena, a quien Sergio ve como el sujeto al que la revolución quiere redimir y como la encarnación del "subdesarrollo" cubano. Décadas después, como han señalado James Buckwalter-Arias, Esther Whitfield, José Quiroga y Rafael Rojas, Cuba ha experimentado considerables "migraciones del libro", para decirlo con las palabras que Quiroga utiliza para describir la compleja fragmentación de la cultura literaria cubana en la era post-soviética (Cuban Palimpsests 115-43). El éxodo implícito en esta expresión se evidenció no sólo en la venta a compradores internacionales de importantes colecciones privadas, sino también en el predominio de ediciones extranjeras de libros cubanos, cuando la crisis económica diezmó la industria editorial de la isla. A partir de allí, los libros de autores cubanos fueron cada vez más difíciles de adquirir en el mercado local y se comenzaron a leer más en el exterior que en Cuba. La expresión "el estante vacío" que utiliza Rojas evoca este proceso de manera elocuente y apunta también a los esfuerzos del Estado de controlar los materiales de lectura de los ciudadanos cubanos. ${ }^{3}$

2 Memorias del subdesarrollo está basada en la novela de Edmundo Desnoes de 1965, quien escribió el guion de la película junto con Gutiérrez Alea.

3 "El Estante vacío" es el título de un ensayo de Rafael Rojas que da título al libro del mismo nombre en el que se discuten aspectos de la política cultural cubana. 
Como sostiene Quiroga, el libro mismo se convirtió en un fetiche que encarnó los ideales de la revolución relacionados con la educación y el colectivismo, y la relación entre la revolución y el libro estuvo "sobredeterminada desde el principio". Según este autor, las características que se aceptan como definitorias la ficción del Período Especial, particularmente la intertextualidad, son una "reacción a los imperativos políticos de la literatura revolucionaria" (Cuban Palimpsests 117, 140, mi énfasis). Del mismo modo, los académicos cubanos que escriben desde la isla, como Jorge Fornet y Margarita Mateo Palmer, enfatizan el desencanto que cruza la literatura cubana de los años noventa (Fornet, "La narrativa" 38-45; Mateo Palmer 157). Pero la biblioteca que se representa en el arte y la literatura demuestra también la compleja textura de las estructuras de sentimiento de la era post-soviética, en las que la desilusión con respecto a la ideología revolucionaria que se considera fosilizada y represiva cohabita con la nostalgia, no sólo por los artefactos culturales perdidos del pasado prerrevolucionario (como los artistas prohibidos u olvidados) sino también por el idealismo revolucionario. La palabra crisis es utilizada por muchos cubanos para describir el Período Especial y por Fornet para designar los valores de esa época que se encuentran amenazados (Los nuevos paradigmas 62). Pero el término también sirve para desmontar el tropo de la biblioteca, porque señala no sólo la desilusión con un sistema arruinado sino también porque, en sus resonancias etimológicas, indica el discernimiento y las elecciones que se llevan a cabo en las complejas respuestas culturales relacionadas con un pasado que se desvanece y un presente disfuncional, y una errancia a través de restos en busca de lo que puede ser recuperado para un incierto futuro.

La biblioteca en la ficción y el cine cubanos contemporáneos genera estas reflexiones porque, más que una colección de libros (privada o institucional), la biblioteca es también un espacio social cuya formación moderna implica circulación. Como tal, la biblioteca posee las características de lo que Michel de Certeau llamó un "lugar practicado", un sitio que se construye a partir de la actividad cotidiana, recurrente, de sus usuarios y no a través de los mapeados oficiales. De Certeau utiliza la idea de "lugar practicado" en su definición de "espacio," que contrasta con el concepto de "lugar": una manifestación del "dominio" de la ley de lo "propio" y de la "estabilidad" (117). A partir de estas definiciones, una biblioteca puede ser considerada, por un lado, como estable, en los términos de de Certeau; es decir, como una esfera institucional con expectativas inscritas oficialmente. Pero, por otro lado, la biblioteca se activa como tal a partir de la improvisación cotidiana. Ben Highmore, basándose en las ideas de de Certeau, sostiene que esa cotidianidad manifiesta la "densidad" de la vida cultural y el 
"rechazo a ser constreñido por los parámetros de lo que se considera la "vida nacional"' (177). La riqueza interpretativa de la biblioteca en la ficción y el cine cubanos de la era post-soviética proviene, en parte, del cuestionamiento cotidiano de esos parámetros oficiales.

Incluso como un "lugar practicado" pleno de significados, en la era de las redes electrónicas la anticuada biblioteca puede parecer un lugar arcaico desde el cual imaginar ciertas impugnaciones. Sin embargo, una de las características más resaltantes de la representación de la biblioteca en las ficciones cubanas es su aura de poder, que evoca diseños y fantasías utópicas de una erudición sobrehumana pero que activa también la subversión de estas fantasías a través de una fuerza generadora de descubrimientos que alteran las perspectivas. Desde la mitológica Gran Biblioteca de Alejandría hasta el impulso borgeano hacia el saber universal total, por un lado, y hacia los libros destinados a repetir otros libros, por el otro, la biblioteca ha sido vinculada desde hace tiempo al impulso enciclopédico de la modernidad de abarcarlo todo (saber, poder o lenguaje) y al desmontaje postmoderno de esos sueños, como sucede en la novela de Umberto Eco, El nombre de la rosa (1980) y su correlato teórico Apostillas a El nombre de la rosa (1984). ${ }^{4}$ Como ha observado Debra Castillo, la biblioteca "representa una estructura de poder y una amenaza a esa estructura (...) un espacio de construcciones jerárquicas, que (...) se ponen constantemente en entredicho como artificiales y carentes de sentido, pero cuyos órdenes no son menos rígidos o poderosos (...)" (viii). Aunque se trate de un espacio secularizado, Castillo agrega que la biblioteca representa tanto "las bases de una comunión espiritual" como "la negación de la espiritualidad y de la comunidad" (viii).

Con los cambios que se han venido desarrollando desde los años noventa, los ciudadanos cubanos han experimentado en su vida cotidiana prohibiciones menos estrictas en contra de lo sagrado, el resurgimiento del turismo como fuente de ingresos, una creciente flexibilidad con respecto a la empresa privada y a las normas que regulan la propiedad, y la reconfiguración de la relación de los ciudadanos con el trabajo. Estos cambios han sido acompañados por periódicas iniciativas estatales de reafirmación ideológica. En este contexto, la biblioteca ofrece un espacio dinámico, casi fantasmagórico, para imaginar las cambiantes relaciones con el poder a través de diálogos improbables entre los distintos sectores de la revolución. Estos escenarios evocan la idea foucaultiana de la biblioteca moderna como un fenómeno que libera "el poder de lo imposible" y que en su multiplicación de potenciales lecturas dentro de lecturas, se asemeja a un discurso "cuya función es mantener no

4 Me refiero al ensayo de Borges, "La biblioteca total" (1939) y a su cuento "La biblioteca de Babel". 
un significado singular o exclusivo (eliminando todos los demás), sino la existencia simultánea de múltiples significados" (Foucault 91, 99). ${ }^{5}$

Incluso bajo las presiones económicas que han afectado las bibliotecas del país, el Estado cubano no ha abandonado el espacio simbólico de la biblioteca ni la regulación de sus actividades. Durante el Período Especial se dio a conocer el polémico "Proyecto de las Bibliotecas Independientes Cubanas" puesto en marcha a partir de una supuesta alianza entre disidentes cubanos residenciados en la isla y donantes estadounidenses de afiliaciones ideológicas diversas, un proyecto que ha sido constantemente rechazado por el liderazgo cubano. ${ }^{6}$ En respuesta a un informe de la agencia internacional ISBN acerca del impacto negativo del Período Especial, el Departamento de Investigaciones de la Biblioteca Nacional José Martí reafirmó la relativa vitalidad del sistema nacional de bibliotecas incluso en medio de las adversidades económicas (Escobar). En este contexto, la biblioteca representada en la ficción y en el cine proyecta una sensación de movimiento y de cambio potencial que coexiste con - y en algunos casos contradice - las imágenes de estancamiento asociadas con los peores años del Período Especial. Este aire de actividad re-energiza la biblioteca como una esfera de negociación ideológica en un momento de ilimitadas expectativas y reactiva las conversaciones pendientes acerca de las clases sociales y la democratización cultural; de la propiedad individual y colectiva, particularmente en lo que se refiere a los artefactos culturales; y, en un período de redefinición de lo individual, acerca del ideal revolucionario de participación ciudadana en la vida cultural.

\section{La biblioteca en el solar: Encuentros cercanos inesperados}

Un escenario recurrente, tanto en la literatura como en el cine contemporáneo en Cuba, es el momento en el que un personaje entra a una biblioteca. Se trata de un momento abrumador en el que el asombro se registra como una poderosa experiencia corporal, preñada de sensaciones físicas y de la promesa de que algo está a punto de suceder. Esta sensación de inminencia evoca el concepto del "poder de lo imposible" (76) que menciona Foucault al hablar de la biblioteca y de la capacidad que ésta tiene de generar significados múltiples, así como la relación que establece Walter Benjamin entre la acumulación de libros y la anticipación

5 Foucault extrapola esta idea de la biblioteca a partir del análisis de las múltiples versiones del libro de Flaubert Las tentaciones de San Antonio, un "monumento" (como la biblioteca) a la "erudición meticulosa" (89) y la encarnación de una biblioteca "en el fuego" (92). Ver al respecto la interpretación que hace Radford de la biblioteca de Foucault como un "lugar dinámico que posibilita nuevos saberes" (408).

6 Con respecto a la controversia generada por este proyecto, ver Hamilton. 
de un descubrimiento (6o-61). En la producción cultural contemporánea cubana esta anticipación emerge, en parte, de la inmensidad de la biblioteca. Pero también proviene de su aparición imprevista en lugares inesperados. Se trata del descubrimiento de un personaje que, a su vez, establece el escenario de otros encuentros improbables entre ciudadanos que ocupan posiciones ideológicas disímiles, lo que genera un acuerdo entre ellos, aunque sea de manera parcial.

El segundo capítulo de la novela Las palabras perdidas (1992) de Jesús Díaz ofrece un ejemplo de este tipo de escenas. En esta obra se representa el esfuerzo fallido de cuatro escritores jóvenes, entre ellos una mujer, de llevar a cabo un proyecto estético innovador: una revista literaria ecléctica, El Güije Ilustrado, dedicada a promover el ideal de la "gran literatura". ${ }^{7}$ Finalmente, la censura estatal acaba con la aventura; un final que se revela a lo largo de todo el texto a través de la contraposición del presente narrativo, ubicado en los años noventa, con el relato de eventos que sucedieron cuando la revolución era todavía joven pero ya se había institucionalizado. Aunque la historia está situada fundamentalmente en los años sesenta, cuando se produjo el principio del fin de la breve luna de miel de los intelectuales cubanos con el Estado revolucionario, Las palabras perdidas encarna las estructuras de sentimiento de principios de los años noventa, cuando aparece la obra y se reformula el problema de la relación del artista con la revolución a través de la mirada crítica que emerge durante el Período Especial. ${ }^{8}$ Los protagonistas anticipan el futuro, en cierto sentido, al intentar recuperar una estética prerrevolucionaria que había sido dejada de lado o desacreditada por el Estado durante el llamado "quinquenio gris" de los años setenta. Pero, al mismo tiempo, el proyecto de la revista está inmerso en el impulso utópico de la revolución.

En esta novela, una enorme biblioteca particular-y la escena anticipatoria en una librería - enmarca el encuentro entre dos de los cuatro güijes que protagonizan la ficción: el Rojo, un aspirante a artista, y el Flaco, un instructor universitario y aspirante a escritor. Estos personajes provienen de sectores sociales distintos y al principio sus propuestas estéticas son diferentes. El Rojo proviene aparentemente de una familia educada y de buenos recursos, y cultiva un arte que pone énfasis en el estilo y que presumiblemente se desvincula de la realidad, mientras que el Flaco, que vive en un solar o casa de vecindad, escribe historias realistas. No obstante, ambos comparten el sueño de un arte con potencial transformador. Su proyecto

7 La frase "gran literatura" aparece a lo largo de toda la novela.

8 Además de la desilusión de los personajes debida a la represión estatal, los indicadores del Período Especial que aparecen en la novela incluyen imágenes de escasez material que son habituales en las ficciones de los años noventa. 
pone en evidencia las tensiones entre una síntesis idealizada de las vanguardias políticas y artísticas y la intención del Estado cubano de poner el arte al servicio de la revolución. En este capítulo, al vincular las posiciones estéticas con las clases sociales, se atribuye de manera implícita un estilo artístico a cada identidad de clase. Aun así, ambos personajes canalizan en sus escritos el impulso utópico de los años sesenta: el Rojo imagina un lenguaje poético que lo abarque todo, mientras el Flaco sueña con una novela que incorpore todos los géneros literarios.

Un encuentro crucial entre los dos personajes da inicio al proyecto de $E l$ Güije Ilustrado en el capítulo titulado "El Flaco y la biblioteca de Alejandría". Allí se contraponen las aspiraciones de estos personajes que se encuentran con la realidad cotidiana en una librería habanera donde se ofrecen las últimas novedades de la literatura europea. Cuando el Rojo ve por primera vez la librería, su reacción revela el poder que ejerce sobre el bibliófilo una enorme colección de libros: "[A]l mirar hacia la librería sintió un mareo, una sudoración, un llamado" (15). Este llamado atrae a los lectores, piensa el Rojo, a un mundo en el que todo es posible, fugas quijotescas y fantásticas, en las que "el loco más cuerdo de la historia entraba a la eternidad montado en las aspas de un molino" (15). La celebración que hace aquí el Rojo del poder de la literatura abarca referencias que van desde Cervantes hasta Joyce, de Rulfo a Grass, de Solzhenitsyn a Vallejo. Como buen representante de la ciudad letrada, debido a su procedencia privilegiada, el Rojo se asombra no sólo del dinámico potencial imaginativo que implica la acumulación de tantos libros juntos en un humilde lugar sino también de la recepción indiscriminada de parte de los clientes ordinarios de la librería que, desde su punto de vista en el que la clase social y la percepción estética están estrechamente vinculadas, carecen de capacidad para juzgar los méritos literarios de los libros que tienen a su alcance. Esta escena se desarrolla, desde la perspectiva del Rojo, como un momento caótico en el que los clientes, acostumbrados a hacer cola interminable para cualquier producto de consumo (uno de los personajes piensa que están vendiendo papas), se llevan todos los libros que pueden cargar: "[U]n enjambre de manos cayó sobre los libros, que empezaron a desaparecer como en un acto de prestidigitación (...). Una suerte de locura se había apoderado de los compradores, que pugnaban por adquirir colecciones completas en las que se mezclaban el oro y el barro" (22).

Aquí, la auto-representación del Rojo, como la única persona capaz de distinguir, al contrario de sus compatriotas, entre el oro y el barro, respalda la implícita conversación que se produce en la novela, a la sombra de la política cultural revolucionaria, con respecto a la relación entre el "buen" arte (esteticista y no comprometido) y el arte "malo" (realista y comprometido). Como 
demuestra Buckwalter-Arias, en lugar de reforzar este binarismo manido, la novela lo cuestiona al ubicar a sus cuatro güijes en una gama variada de posiciones vinculadas a la relación del arte con la vida, al ensayar un amplio espectro de estilos y al mostrar las contradicciones entre las diferentes filosofías estéticas y las prácticas concretas, así como al revelar similares contradicciones dentro de la misma novela (50-82). Pero el encuentro en la librería y la escena en la biblioteca que aparece a continuación también revelan el retorno contemporáneo de una reprimida conciencia de clase no resuelta, donde la sensibilidad artística es reformulada como una medida del estatus social. El Rojo se imagina a sí mismo por encima de los otros clientes de la librería no sólo porque cree que ellos carecen de gusto literario, sino también porque son sólo consumidores determinados por el modo en que funciona el mercado (sea éste libre o regulado). El Rojo se enorgullece de no haberse rebajado nunca a comprar libros ("la liaison del verbo vender con el sustantivo libros era repugnante" [14]) y prefiere robárselos (en las tiendas o a los amigos), escondiéndolos en la carátula vacía de un libro de Otto Kuusinen llamado Manual del Marxismo-Leninismo. Por el contrario, el Flaco compra grandes cantidades de libros y las especulaciones del Rojo al respecto revelan las tensiones que existen entre sus propios prejuicios y el objetivo igualitario de la revolución, según el cual todo cubano debe tener acceso a la cultura letrada: "¿El Flaco sería un revendedor? No, no tenía tipo. Probablemente era algo muchísimo más siniestro, un oportunista nuevo rico que se había hecho con alguno de los palacetes abandonados por los burgueses de Miramar y que ahora compraba libros por metros para adornar paredes" (23). ${ }^{9}$ En estas especulaciones del Rojo queda implícita la idea de que los "nuevos ricos" habaneros - aquellos cuyos servicios a la revolución fueron recompensados con una de las casas que abandonaron sus compatriotas adinerados que se fueron al exilio-carecen de la aristocracia del gusto de la que se vanagloriaba la vieja intelligentsia con la que el Rojo se identifica.

Este renovado clasismo, envuelto en una crítica a la política cultural regulatoria del Estado, es frecuente en las expresiones artísticas cubanas de la era post-soviética y aparece, por ejemplo, en la mordaz parodia que elabora Arturo Infante del saber cultural de los cubanos en el corto Utopía (2004). Pero al ubicar esta renovada conciencia de clase en una biblioteca se ofrece una interpretación

9 La referencia relacionada con los revendedores de libros refuerza el doble marco temporal de la novela ya que la venta de libros a los turistas se convirtió en una actividad común durante los años noventa, fecha en la que se publica la novela, en vez de los años sesenta, que es la época en la que la ficción se desarrolla. 
más penetrante en la que la promesa incumplida de la revolución, con respecto a la democratización cultural, se cuestiona al mismo tiempo que se reactiva. Cuando el Flaco le pide al Rojo que lo ayude a cargar sus bolsos llenos de libros hasta el remoto vecindario habanero donde vive, la novela representa el viaje desde El Vedado, que es el centro de gran parte de la vida intelectual de la ciudad, hasta Luyanó como un descenso hacia una "terra incognita" para el Rojo, quien se siente incómodo ante la pobreza, las marcas raciales y el habla particular de los habitantes de la zona (Díaz 28). El Flaco le dice casi con orgullo que vive en un solar. Cuando retira la desvencijada cortina que separa el espacio que el Flaco comparte con su madre del resto del solar, la impresión del Rojo frente a la monumental biblioteca reitera el asombro que experimentó frente a la librería. En este caso también se revelan las razones contradictorias de su sorpresa:

El Rojo quedó boquiabierto. El cuarto (...) estaba literalmente tapizado de libros. Tres de las cuatro paredes del altísimo puntal estaban cubiertas por enormes libreros improvisados a base de tablones y ladrillos; en los rincones había paquetes amarrados con cordel y cajas desbordadas de libros. Junto a la cuarta pared, bajo la ventana de barrotes sin pintar se veía un refrigerador descascarado, un tosco escaparate color crema con el techo atestado de libros, una venerable máquina de coser con la tapa cubierta de libros, una mesa despintada con un cajón de libros debajo, un fogón de luz brillante encima, dos sillas y una butaca desfondada por el peso de los libros. Casi en el centro del habitáculo había una cama camera con el bastidor hundido. Sobre el ángulo que formaban dos de los libreros, un altar de Santa Bárbara, al que de milagro no le había puesto un libro encima (33, mi énfasis).

El poder que tiene la biblioteca de asombrar al Rojo en esta escena se deriva no sólo de su incontenible proliferación sino también del lugar inesperado en el que se encuentra, un solar habitado por gente que él considera inculta. Al condensar las distintas visiones que estos personajes tienen sobre el arte, este escenario, paradójicamente, los acerca. Cuando el Rojo comenta que debe ser difícil para el Flaco distanciarse del precario ambiente que lo rodea para poder escribir, el Flaco rechaza la suposición implícita de que la creatividad se relaciona con la ubicación social: "¿Y qué coño tiene que ver el solar con el talento? (...) ¡Dime! ¿Qué coño tiene que ver?” (Díaz 46). Al mismo tiempo, la inmensa biblioteca que tiene el Flaco en el solar proporciona el espacio de encuentro en el que, más allá de sus orígenes sociales, los personajes pueden discutir sus visiones divergentes acerca del arte, donde el Rojo lee en voz alta un cuento escrito por el Flaco y le comenta sus impresiones, y donde planean el lanzamiento de la revista 
experimental, cuya creación y eventual destino constituye gran parte del soporte anecdótico de la novela.

A pesar de sus profundos desacuerdos y de la ruptura final del grupo, debido a las pugnas internas y al impacto de la represión del Estado, este capítulo de Las palabras perdidas sugiere que, en el discurso cultural de la Cuba post-soviética, la biblioteca ocupa un lugar que excede el espacio que le otorga la política oficial, lo que trae a la mente la lectura por Highmore de de Certeau. En contraste con la reunión que mantuvo Fidel Castro con los intelectuales y artistas en 1961 en la Biblioteca Nacional, el encuentro del Flaco y el Rojo en la biblioteca, aunque conflictivo, se desarrolla a partir del diálogo y no del discurso didáctico. Este modelo paradójicamente evoca el concepto del Che Guevara con respecto al potencial pedagógico de los intercambios entre las diferentes clases sociales que podían producirse en las campañas de alfabetización. Al mantener la perspectiva desencantada con respecto a los ideales revolucionarios que es característica del Período Especial, la novela registra en última instancia el fracaso de la camaradería entre los güijes y de la misma revista debido a la intervención estatal, un doble colapso que se representa a través de la destrucción de la biblioteca del Flaco durante un intenso aguacero. Pero la novela también propone una reflexión sobre los ideales que podrían rescatarse, porque la biblioteca se muestra al mismo tiempo como el lugar del desencanto pero también como el espacio que permite una renovada consideración del poder de los encuentros sociales fortuitos, poder inscrito en los ideales revolucionarios de erradicación de las diferencias y la construcción de comunidades que trasciendan las clases sociales.

En este capítulo, de manera significativa, Díaz recicla críticamente el ideal revolucionario de solidaridad entre clases otorgándole al Flaco el papel de custodio intelectual, de bibliotecario, que por vivir en un lugar modesto se ubica entre los beneficiarios de la revolución. La novela refuerza la posición privilegiada del Flaco al intercalar su relato de los años sesenta con las reflexiones que muchos años después hará desde la Torre Ostánkino de Moscú y a través de la impresión que recibimos al final de que la novela que estamos leyendo puede ser un texto escrito por el Flaco, recuperando el olvidado lenguaje literario de los güijes. Por el contrario, el ejemplo más conocido de la biblioteca en el solar como escenario del diálogo entre interlocutores imprevistos — que aparece en la película nominada al Oscar Fresa y chocolate (1993), de Tomás Gutiérrez Alea y Juan Carlos Tabío- escenifica una relación inversa entre el arte y la clase social. La película se basa en el cuento titulado El lobo, el bosque y el hombre nuevo de Senel Paz, quien también escribió el guion cinematográfico. En una de las primeras escenas de la película, Diego, el disidente intelectual homosexual, lleva al joven comunista David al bullicioso 
solar en la que se encuentra su guarida. La guarida está totalmente ocupada por la ecléctica biblioteca de Diego, compuesta de una desordenada colección de objetos artísticos y libros cubanos y extranjeros, muchos de ellos recuperados del pasado cubano o contrabandeados desde el exterior en el presente. Estos materiales dispares evocan lo que para Benjamin constituye los "prismáticos bordes" que definen una verdadera "biblioteca viva" (66). David, la contraparte social del Flaco, es un estudiante universitario de origen provinciano que vive en La Habana con una beca del Gobierno, un beneficiario de las reformas llevadas a cabo por la revolución. David sigue a Diego hasta su casa bajo la promesa de que va a recibir algunos libros en préstamo y para recuperar unas fotos suyas que Diego dice tener. Con el fin de producir una distancia con el presente del relato, como en Las palabras perdidas, esta película de 1993 ubica la historia en un conflictivo momento del pasado. El año en que estos personajes se encuentran es, significativamente, 1979, cuando finaliza una década marcada por la activa persecución oficial de homosexuales, y un poco antes de 1980, el año en el que se produjo el éxodo del Mariel, que fue la culminación de las repetidas confrontaciones entre el Estado y sus disidentes. Sin embargo, Fresa y chocolate, igual que la novela de Díaz, evoca el aura de los inicios del Período Especial con imágenes de escasez, de un intenso mercado negro, y de íconos que representan tanto la nostalgia por una estética prerrevolucionaria como por el idealismo original de la revolución.

$\mathrm{Al}$ abrigo de la biblioteca de la guarida, Fresa y chocolate se desarrolla como una conversación virtual entre los beneficiarios de la revolución, como David, y sus disidentes que, como Diego, han sido perseguidos debido a que se han desviado del modelo de cubanidad que es el revolucionario heterocéntrico y disienten de los parámetros culturales impuestos por el Estado. Con la biblioteca de Diego funcionando como salón de clases, como he mencionado en otra parte, la película también reformula el encuentro didáctico entre el profesor y el estudiante característico de las campañas alfabetizadoras de la revolución, convirtiéndolo en un curso privado de alfabetización cultural (Unruh 203). Sin embargo, en lugar de considerar el proyecto educativo del Estado como un fracaso, la película atribuye sus limitaciones a la ortodoxia ideológica y a la represión. Diego realza la educación artística que David ha recibido del sistema estatal, corrige las ideas que tiene sobre la homosexualidad y lo anima a abandonar el realismo socialista lleno de consignas que caracteriza sus ficciones. Esta tutoría recuerda los comentarios críticos que hace el Rojo al cuento "Fidelidad" escrito por el Flaco en Las palabras perdidas (Díaz 38-41).

Al igual que en la novela de Díaz, en Fresa y chocolate la biblioteca ofrece el espacio apropiado para esas transformaciones, porque está impregnada del "poder 
de lo imposible" del que habla Foucault (67), que permite los intercambios directos entre las distintas posiciones que se pueden tomar frente a la revolución. Una escena posterior al primer encuentro entre Diego y David en la biblioteca de la guarida muestra el impacto que produce la colección mientras la cámara —a través de la perspectiva de David - hace un paneo por la habitación llena de libros, revistas, esculturas religiosas y fotografías de personajes del arte y la literatura. La biblioteca incluye una pared en la que se exponen diferentes objetos que David considera al mismo tiempo acogedora y extraña, porque junta en un mismo espacio lo familiar - una foto de José Martí, una linterna de las que se usaban en las campañas de alfabetización - con lo desconocido - una fotografía del poeta Lezama Lima cuyo trabajo fue durante un tiempo condenado por el Estado. En una escena parecida a la reacción física inicial que tiene el Rojo frente a la biblioteca del solar, en Fresa y chocolate se muestra el poder que ejerce la colección de la guarida en el modo en que el cuerpo de David se tensa o se relaja. El nostálgico fondo musical, tomado de la partitura de José Vitier, enfatiza la atracción que ejerce la biblioteca a medida que David, fascinado, observa los objetos expuestos en la pared y en los estantes.

Una danza verbal de avances y retrocesos caracteriza la amistad que se va desarrollando en la película entre dos hombres que ocupan posiciones contrarias con respecto a la política cultural de la Cuba de finales del siglo XX: un auténtico creyente en las promesas de la revolución y un disidente desilusionado a quien se le prohibió participar en las campañas de alfabetización y ha sido despedido de su último trabajo por expresar una visión crítica. Lo que al principio parece imposible, finalmente florece en el espacio de la biblioteca de la guarida que acoge la improvisación. Mientras David se abre más al contacto con la biblioteca y con el archivo cultural prohibido que contiene, la película representa visualmente el modo en que se produce la igualdad entre los dos personajes al ubicarlos frente a frente en sus últimas discusiones, en contraste con escenas anteriores en las que Diego mira desde arriba a David mientras le ofrece información. Cuando David agrega a la exhibición de la pared una bandera revolucionaria del 26 de julio y fotos de Fidel y el Che, sumando un "borde prismático" benjaminiano a la dinámica y cambiante biblioteca de Diego, pronuncia un apasionado discurso a favor de una revolución renovada que pueda aceptar las posiciones y los íconos de la diversidad cultural, artística y política desplegados en la pared de la biblioteca de la guarida. El resultado es una exhibición ecléctica frente a la cual Diego ofrece un brindis por el "comunismo democrático" que evoca la noción foucaultiana de la capacidad de la biblioteca de escenificar una multiplicidad de significados (76).

Los críticos han señalado que al representar al final la salida de Diego al exilio, la película se distancia de las posibilidades de rectificación y reconciliación 
que ha escenificado a lo largo del desarrollo de la amistad entre los dos personajes y frena todo propósito de reconciliación con la sexualidad gay. ${ }^{10}$ No obstante, en el contexto de las discusiones no resueltas sobre las clases sociales en las representaciones post-soviéticas de la biblioteca, me gustaría proponer una visión diferente. Más allá de la crítica que hace a las limitaciones a la libertad de expresión del Estado revolucionario, en Las palabras perdidas de Díaz se le asigna al Flaco la administración de la biblioteca, un personaje de orígenes modestos que vive en un solar y quien considera que la clase social no tiene que ver con el talento o el saber; esta posición se reafirma en la novela a partir de la autoría implícita del texto, atribuida a este mismo personaje. Sin embargo, Fresa y chocolate restaura la equivalencia entre la sensibilidad estética y una intelligentsia aristocrática al encarnar al culto dueño de la biblioteca - el que custodia el olvidado archivo del arte y el pensamiento cubano y universal - en un personaje que, aunque es generoso con sus vecinos, se identifica más con la élite de la ciudad letrada — supuestamente desaparecida ya en la Cuba socialista - que con la gente que lo rodea.

De modo que, aunque la película no ofrece mucha información sobre el origen social de Diego, el hecho de que tenga en su poder unas tazas de porcelana que pertenecieron a la prestigiosa familia de la escritora Dulce María Loynaz (1902-1997) sugiere un linaje más privilegiado que el de David, que tiene sus raíces en la zona rural del país. De ahí que, a pesar de lo atractivo del personaje de Diego (del que es casi imposible distanciarse, debido a la conmovedora representación que hace el actor Jorge Perugorría), sus bruscos ataques criticando la falta de sensibilidad cultural de otras personas, aunque llenos de agudeza, ponen en escena un clasismo renovado con sesgos racistas. Esto puede verse cuando David rechaza el té que se le ofrece y Diego contrasta la "civilizada" costumbre inglesa de tomar té con el supuesto retraso cubano - racialmente marcado-que se evidencia en la preferencia por el café, al cantar la conocida canción cubana "Ay, mamá Inés": "Todos los negros tomamos café". Igualmente, Diego utiliza el canto operático para burlarse satíricamente del modo en que la falta de alimentos básicos atormenta a los cubanos corrientes ("Vecina, ¡llega la cebolla!") y parodia con furia el habla callejera cubana (específicamente el acento afro-cubano) para declarar que la gente que utiliza ese tipo de lenguaje es considerada patriota mientras la gente como él no lo es. En contraste con la defensa que hace el Flaco del solar, como el lugar apropiado para la biblioteca y como generador de talento, Fresa y chocolate sugiere que la inteligencia y el gusto del esteta dueño de la biblioteca sobreviven a pesar de estar ubicados en un solar. Aunque separada por casi tres décadas de

10 Ver Quiroga (Tropics of Desire 124-44) y Bejel. 
Memorias del subdesarrollo, el primer gran triunfo cinematográfico de Gutiérrez Alea, y a pesar de que sus personajes tienen poco en común con Fresa y chocolate, la opinión que tiene Diego de sus conciudadanos como seres subdesarrollados en términos culturales mantiene una curiosa similitud con el tono condescendiente que utiliza Sergio con respecto a su novia Elena y sus respuestas indiferentes frente a las exposiciones de arte, las librerías y la biblioteca de Hemingway.

Estos ejemplos de bibliotecas de solar revelan tensiones recurrentes relacionadas con las clases sociales y la democratización cultural en Cuba, décadas después de los intensos cambios que el Estado revolucionario implementó en busca de la igualdad social. Se podría decir que estas bibliotecas específicas particularmente la guarida de Diego, donde los dos hombres se pueden encontrar sin someterse al riesgo que implicaría que se vieran en público - son construidas como refugios seguros, aislados de la vida cotidiana concebida por de Certeau. Y, por supuesto, tanto la del Flaco como la de Diego son colecciones privadas, pero estas bibliotecas de solar tienen también un fuerte carácter público. La exhibición de objetos en la pared de la guarida de Diego sugiere una dinámica entre lo interno y lo externo y evoca las obras de arte pintadas sobre el lado occidental del muro de Berlín antes de su demolición en 1989. Para el espectador local, una referencia más cercana son las vallas en las que el Estado cubano despliega en los espacios públicos las consignas de la revolución.

En ambas obras las bibliotecas tienen límites porosos y las conversaciones son interrumpidas por otros personajes que entran y salen, por el ruido del vecindario y de la misma ciudad. Esta permeabilidad marca la riqueza interpretativa que le otorga a estas bibliotecas el hecho de que estén ubicadas en un solar, que en Cuba es por definición un espacio sobrepoblado en el que las divisiones entre lo privado y lo público con frecuencia se nublan. En las bibliotecas de solar del Flaco y Diego, la actividad intelectual, la lección o la lectura en voz alta, se intercalan con actividades cotidianas como comer, cocinar, hacer compras y chismear. Incluso, las tácticas utilizadas por los personajes para evadir la vigilancia oficial, tales como esconder las conversaciones con música a todo volumen, evocan la propuesta de Highmore quien, siguiendo a de Certeau, sostiene que el imaginario que surge de los lugares practicados se distancia del imperio de la ley (118). Es en ese sentido que, en la era post-soviética que ha sido testigo de una renegociación tanto en la literatura como en el cine de los valores revolucionarios que colocaban el deber público por encima de la autonomía individual, el tropo de la biblioteca socava los límites entre lo público y lo privado para explorar cuestiones recurrentes acerca de la propiedad cultural y el compromiso de los ciudadanos comunes con la vida literaria. 


\section{¿De quién son los libros? Entre las colecciones privadas y el acceso público} La representación de bibliotecas privadas que se hace en Las palabras perdidas y en Fresa y chocolate como lugares permeables y semi públicos se corresponde no sólo con las políticas de democratización cultural impulsadas por la revolución sino también con una larga tradición cubana que ubica la práctica de la lectura en una red de multifacéticas actividades culturales comunitarias. Mucho antes de que triunfara la revolución de 1959 esta tradición de lectura estaba presente en gran cantidad de eventos - lecciones, exposiciones de libros, ejercicios de aprendizaje para niños y jóvenes - promovidos por las bibliotecas públicas y por las bibliotecas privadas que estaban abiertas al público. ${ }^{11} \mathrm{El}$ hecho de que una biblioteca cubana esté oficialmente abierta al público no significa que tenga un préstamo circulante sino que en ella se posibilita la circulación de una comunidad de lectores a partir de actividades relacionadas con la lectura y la cultura artística. La promoción, por parte del Estado revolucionario, de una red de bibliotecas regionales, centralizada sin embargo en La Habana, canalizó esta tradición prerrevolucionaria hacia el ideal de una democratización cultural que, como afirma Carlos Robió, imaginaba la lectura más como una forma de participación social que como una actividad individual (473).

Los estudiosos de la revolución cubana han sostenido por mucho tiempo el ideal de una amplia participación de la ciudadanía para definir la noción estatal de democratización cultural. Esto comenzó, por supuesto, con las campañas de alfabetización que se extendieron por todo el país y que intentaron promover la habilidad de leer como una forma activa de participación ciudadana. ${ }^{12}$ Antonio Kapcia y Par Kumaraswami han resumido de esta manera la genealogía de esas iniciativas: los "instructores de arte" de los años sesenta (enviados a recorrer toda la isla como maestros culturales); los "aficionados" de los años setenta (que eran artistas principiantes); y las Casas de la Cultura municipales de los años ochenta (226). Según Kapcia y Kumaraswami, este proceso se acelera en los años noventa, que es el período en el que se enfoca su análisis, con el relanzamiento de la Feria del Libro de La Habana (que había comenzado originalmente en 1982) como una "ritualización de la pertenencia cultural" (167). Pero, como he señalado en el caso de Sergio en Memorias del subdesarrollo (1968) de Gutiérrez Alea, los ideales que sostienen estas iniciativas culturales ya habían sido cuestionados desde

11 Con respecto a la historia de las bibliotecas cubanas, ver Mayol y Orne; Carranza y Jiménez López; y en el Diccionario de la Literatura Cubana, las entradas sobre la Biblioteca de la Sociedad Económica de Amigos del País (125-26), la Biblioteca Gener y Del Monte (127-28), la Biblioteca Municipal de La Habana (128) y la Biblioteca Nacional José Martí (128-30).

12 Sobre la campaña de alfabetización y los proyectos educativos de la revolución, ver Fagen (33-68). 
temprano por algunos intelectuales. Del mismo modo, Kapcia y Kumaraswami sostienen que estos experimentos de participación cultural se encontraron desde el principio con el escepticismo de los productores y de la élite cultural que cuestionaban las ideas de participación cultural universal y de propiedad colectiva de los productos culturales (167-69). Estas tensiones se intensificaron en el Período Especial a medida que el mercado (no tan) clandestino del libro, que surgió como una de las estrategias para superar la crisis económica, diezmó las bibliotecas privadas cubanas al punto de poner en peligro la noción misma del archivo cultural nacional, y reactivó las interrogantes acerca de la propiedad cultural individual y colectiva.

Las conflictivas visiones de la biblioteca como el lugar de la búsqueda intelectual individual, por un lado, o como un archivo del patrimonio nacional o como promotora de la pertenencia social, por el otro, impregnan las novelas de Leonardo Padura, particularmente sus novelas policiales, cuyo protagonista es Mario Conde, detective desilusionado y aspirante a escritor. Este corpus, escrito por el más leído de los novelistas cubanos contemporáneos, dentro y fuera de la isla, incluye las novelas iniciales recogidas bajo el título general de Las cuatro estaciones, en las que Conde trabaja para la policía de La Habana, y tres novelas posteriores, Adiós Hemingway (2001), La cola de la serpiente (2001) y La neblina del ayer (2005), en las que ha dejado de ser policía pero todavía se involucra de manera ocasional en la investigación de crímenes ${ }^{13}$. Aunque los casos que debe resolver muestran la hipocresía y la corrupción oficiales durante los años en los que se ubica la ficción — de 1989 a 2003-, el misterio mismo suele ser menos importante que los descubrimientos que hace Conde de que la sociedad cubana post-soviética que lo rodea en su vida adulta está muy lejos del imaginario cultural revolucionario de su juventud.

Leídas en conjunto, las novelas policiales de Padura representan la reeducación y el progresivo desencanto de un hijo de la revolución - y de la generación que él encarna - en medio de las realidades de la Cuba de finales de siglo XX y principios del XXI. A través de las escenas retrospectivas que aparecen en las siete novelas es posible reconstruir una narrativa de aprendizaje que comienza en los años de formación de Conde en el instituto preuniversitario llamado La Víbora. Se trata de un tiempo y un lugar que el personaje recuerda con nostalgia. Al contraponer

13 En noviembre 2013, varios meses después de la publicación original en inglés del presente texto, apareció la novela Herejes de Padura, también protagonizada por Mario Conde, aunque en esta obra, la biblioteca no constituye un eje interpretativo central. 
estas dos líneas temporales, el pasado revolucionario y el presente post-soviético, las novelas de Padura reactivan los ideales que sostenían su misma formación revolucionaria, que incluyen la camaradería, la esperanza de igualdad social y una profunda fe en el valor de la educación. Como se enfatiza particularmente en las novelas Máscaras (1997), Adiós Hemingway (2001) y, sobre todo, en La neblina del ayer (2005), la biblioteca es un lugar central en la educación de Conde y todavía más en su reeducación en el presente post-soviético. La biblioteca en la obra de Padura, que culmina en La neblina del ayer, contiene todas las disputas que Conde tiene que resolver entre su formación individual como escritor y pensador y los vestigios de su compromiso con un concepto más amplio de ciudadanía responsable, que proviene de la época de su formación revolucionaria.

Si el ideal de democratización cultural promovido por la revolución sostenía que todos los ciudadanos cubanos debían tener acceso a los libros, el tropo de la biblioteca en las ficciones policiales de Padura ofrece una vía para plantear la duda acerca de en qué consiste exactamente una ciudadanía educada en la Cuba contemporánea. La novela Máscaras, que es la tercera de la tetralogía inicial, representa claramente esta reorientación. En esta novela se muestra por primera vez la obsesión de Conde con las bibliotecas cuando una profunda sensación de atracción y misterio emana de la impresionante biblioteca de Alberto Marqués, un excéntrico dramaturgo homosexual que trabaja en un teatro y a quien Conde, que en ese momento es todavía un policía, debe entrevistar varias veces para resolver el asesinato de Alexis Arayán, el hijo gay de un diplomático. Duplicando la misma escena en la que el Rojo entra por primera vez en la biblioteca del solar del Flaco en Las palabras perdidas, o cuando David entra a la guarida de Diego en Fresa y chocolate, una fuerte respuesta sensorial marca la primera vez que Conde observa esta colección de libros: "Entonces descubrió el origen del olor que no había podido clasificar al principio: era el perfume opresivo y magnético del papel viejo, húmedo y empolvado, que salía de aquel recinto, también oscuro, donde estaba lo que debía ser la biblioteca de Alberto Marqués, seguramente poblada de obras y autores excluidos por ciertos códigos y de exóticas maravillas editoriales, inimaginables para un lector del común (...)" (Máscaras 52).

En esta escena Conde es ese lector común y, por extensión, ocupa el lugar del ciudadano corriente. En escenas parecidas a las de los intercambios de Diego y David en Fresa y chocolate, la reeducación que Conde recibe del Marqués a través de sus conversaciones abarca los libros y los escritores cubanos que fueron marginalizados periódicamente por el Estado. Se trata de textos que fascinan a Conde porque han estado ausentes de su propio repertorio. Un segundo aprendizaje que recibe el policía es el relacionado con el mundo de la comunidad de 
homosexuales en La Habana. Pero en Máscaras la mayor parte de las lecciones se desarrollan en la sala de la casa del Marqués, porque Conde debe ganarse el acceso a la biblioteca a través de su propia reeducación en el ejercicio de la tolerancia y asumiendo una visión más incluyente del archivo de la literatura cubana. A partir de una reformulación implícita del concepto revolucionario de ciudadanía que concibe la alfabetización como la llave que permite el ingreso al archivo cultural, el acceso a la biblioteca en Máscaras premia el acercamiento a los libros con una mente abierta que pueda ir más allá de lo que se considera el archivo oficial de ese momento y pone en escena el rescate de artefactos culturales perdidos, particularmente la obra del poeta y dramaturgo Virgilio Piñera y su pieza teatral Electra Garrigó (1948). Cuando finalmente Conde se gana el derecho a entrar en la biblioteca, el Marqués hace notar que: "[U]sted que es un escritor debe saber que (...) está asomándose a lo eterno, a lo imborrable, a lo magnífico, a algo contra lo que nadie puede, ni siquiera el olvido" (225). Más aun, cuando el Marqués le muestra a Conde las obras que ha escrito y escondido en su biblioteca, inscribe de manera implícita esta habitación entre los lugares practicados, en el sentido de de Certeau. En estos espacios en los que, a través de la agencia de quienes los atraviesan, se exceden las reglas que los rigen: "[aquí] no me dejaron publicar ni dirigir, pero nadie me podía impedir que escribiera y que pensara" (Máscaras 226).

Incluso cuando se le permite ingresar a bibliotecas clandestinas privadas que lo impresionan, Conde mantiene un compromiso perdurable, aunque conflictivo, frente a estos espacios que concibe idealmente como templos sagrados para iniciados, pero también como espacios sociales cuyos custodios están obligados a compartir con otros. La ambivalencia de Conde frente a las bibliotecas privadas que tanto admira evoca la propuesta de Benjamin de que las bibliotecas de los coleccionistas privados, aunque sean más objetables desde el punto de vista social que las bibliotecas públicas, se sostienen sobre el aura de una herencia manifestada en el sentimiento que tiene su dueño "de una responsabilidad que liga al propietario con su dominio" (67). Según Benjamin, esta actitud de responsabilidad en un coleccionista de libros que se imagina como heredero, se une al hecho de que "la característica más noble de una colección será siempre la posibilidad de transmitirse por herencia". La noción de una colección de libros como un tipo particular de herencia - específicamente como legado cultural que puede ser transmitido - está presente en todas las novelas policiales de Padura. Máscaras, por ejemplo, parece legitimar la biblioteca privada del Marqués en la Cuba socialista porque esta colección recupera y transmite - a través de la tutoría entre el Marqués y Conde - artefactos perdidos que son inadmisibles en 
el archivo nacional constituido por el Estado revolucionario. En este contexto, la biblioteca privada asume la responsabilidad de transmisión del legado que no ha sido asumida por las instituciones públicas encargadas de esa tarea.

En el mundo ficcional de Padura, de hecho, las bibliotecas privadas parecen ser, a veces, más accesibles que las bibliotecas públicas. En Adiós Hemingway, donde el descubrimiento de unos restos humanos lleva a Conde, ahora ex-policía, a investigar una muerte ocurrida en 1958, se muestra una escena de Conde trabajando en la Biblioteca Nacional. Aquí, mientras indaga sobre la vida de Hemingway, el protagonista disfruta de un espacio inusualmente vacío mientras los estudiantes universitarios están de vacaciones. Al respirar el "aire apacible" de la biblioteca vacía, una institución pública monumental que se convierte en santuario para la reflexión individual, Conde es dominado por la sensación gozosa de "zambullirse entre libros" (133). Al mismo tiempo, Conde reactiva un ideal perdido de la Biblioteca Nacional como un espacio de pertenencia cultural y orgullo colectivo cuando descubre, sorprendido, la riqueza de la colección de libros de Hemingway: "Algo parecía funcionar en la isla" (133). Aun así, se da cuenta de los vacíos de la colección y sospecha que la biblioteca nacional no logra transmitir de manera responsable su legado a los ciudadanos comunes y corrientes. Conde se imagina que seguramente la única manera que se logró cierto nivel de eficiencia de parte de los funcionarios de la biblioteca fue una llamada oficial de parte de la policía que anticipó su visita. Con demasiada frecuencia, piensa Conde, los "cabrones" que están a cargo del archivo cultural de la nación son, por decir lo menos, "misteriosos" cuando se trata de compartir ciertos libros (132). De ahí que la biblioteca no cumpla con el ideal de promover la participación ciudadana en el acervo cultural, un ideal al que Conde no quiere renunciar.

La neblina del ayer, ubicada a principios del nuevo milenio, revela la ambivalencia no resuelta del ex-policía con respecto a la biblioteca como iniciativa particular o como generadora de una participación cultural más amplia. Retirado oficialmente del trabajo policial, Conde es ahora un intermediario que adquiere colecciones privadas de libros para revenderlas. En el vecindario habanero de El Vedado, Conde se encuentra con la inmensa biblioteca que ha dejado el difunto Alcides Montes de Oca, un empresario habanero que había respaldado la revolución durante un breve período. En los años sesenta, Montes de Oca se fue a los Estados Unidos y dejó a Nena, su secretaria (y ocasional amante) a cargo de la casa y de la biblioteca que había sido adquirida por la familia desde principios del siglo XX, época de la fundación de Cuba como república independiente. Los hijos de Nena -Dionisio y Amalia, ya septuagenarios - quieren vender los libros para sobrevivir. La colección es representada como definidamente cubana, 
un archivo enciclopédico borgesiano que, según Conde se lo imagina, contiene todos los libros escritos en Cuba o sobre Cuba, desde los tonos inestimables que pertenecieron a los criollos dueños de esclavos hasta el repertorio de textos proscritos por la revolución de 1959. A través de la imaginación de Conde la novela transforma la biblioteca particular en un poderoso imaginario cultural con un público lector implícito que incluye tanto a los colonizadores criollos, como a los ciudadanos letrados de la Cuba prerrevolucionaria, a los revolucionarios y a sus otros excluidos.

Al igual que en Máscaras, el impacto inicial que siente Conde de manera tangible frente a la biblioteca bordea lo sobrenatural. La colección es un "prodigio" que simultáneamente lo paraliza y lo obliga a estar presente (24). La atracción que siente Conde frente a esta biblioteca es en parte nostálgica, pero ya no se trata de una añoranza por el repertorio marginalizado por el Estado revolucionario, como sucede en Máscaras, sino más bien del recuerdo del aprendizaje literario que obtuvo, como hijo de esa revolución, del bibliotecario del instituto preuniversitario de La Víbora, llamado Cristóbal el Cojo. Allí el Conde aprendió a amar las bibliotecas y los libros "del mismo modo en que los creyentes adoran sus templos: como sitios sagrados, donde no está admitida la profanación" (164). Es desde esta perspectiva que Conde ve la biblioteca de Montes de Oca como un "santuario perdido en el tiempo" que puede ser ultrajada si sus libros se ponen a la venta (Neblina 25). Pero la biblioteca en La neblina del ayer es profanada cuando Dionisio, uno de sus custodios, muere allí mismo, asesinado por su hermana, que es la otra encargada de cuidar la biblioteca. Los múltiples recovecos del argumento, que van más allá del alcance de este texto, incluyen el descubrimiento que hace Conde de la presencia en la vida de Montes de Oca de una popular cantante de los años cincuenta, Violeta del Río, cuyo destino final obsesiona al investigador. En el proceso de resolver el misterio de la vida de Violeta y del asesinato de Dionisio, la novela disipa la seductora neblina del pasado prerrevolucionario cubano al desenmascarar la deplorable historia de injusticias sociales, corrupción oficial y conflictos familiares que la biblioteca representa. La novela también dibuja equivalencias cercanas entre el crimen, el racismo y la miseria humana de la época de Batista con la devastadora realidad del submundo habanero post-soviético que Conde descubre y frente al cual se lamenta, no sólo por quienes habitan ese mundo sino también por los ideales perdidos de su generación: "[L]a muerte de tantos sueños, esperanzas y responsabilidades históricas" (Neblina 314).

Lo que al final de la novela se salva, sin embargo, es el destino de los libros de la colección de Montes de Oca. Los libros que quedan después de la muerte o 
encarcelación de quienes estaban encargados de custodiarlos serán depositados en la Biblioteca Nacional, lo que para Conde es alentador, porque significa que, al menos en principio, todavía podrán ser leídos por lectores cubanos. Esta opción, aunque no sea la ideal, debido a que los lectores comunes no necesariamente van a tener acceso a los libros, es preferible a la dispersión de la herencia cultural cubana a través de la venta en el mercado internacional, frente al cual Conde sigue teniendo dudas. El investigador imagina la venta de las bibliotecas particulares cubanas como el acto de donar sangre a cambio de comida, un proceso a través del cual "centenares de bibliotecas privadas dejaron de ser fuente de ilustración, orgullo bibliófilo y acopio de recuerdos de tiempos posiblemente felices, y trocaron su olor a sabiduría por la fetidez ácida y vulgar de unos billetes salvadores" (17). Conde se consuela pensando que él sólo rastrea los libros pero no se dedica de hecho a venderlos.

Desde su primer viaje a la biblioteca de Montes de Oca, Conde comienza a organizar y separar los ejemplares: algunos van a poder venderse, otros deberían ir a la Biblioteca Nacional y algunos, tal vez, podrían ir a parar a su propia colección. En este trasiego de libros se representa la lucha de Conde por reconciliar sus antiguos ideales de democracia cultural y propiedad colectiva con la realidad contemporánea en la que la crisis económica obliga a la venta de libros y el valor diferencial que de hecho le atribuyen los distintos sectores cubanos a las bibliotecas particulares. Estas realidades ponen en entredicho el ideal heredado por Conde según el cual la biblioteca es un espacio común "inviolablemente neutral y colectivo" (165), sobre todo cuando Amalia cuenta su propia experiencia en relación a la biblioteca, marcada por su origen de clase, de cuyo cuidado ha estado a cargo por 43 años: "[S]iempre le he tenido (...) mala voluntad a esos libros, no por los libros en sí, sino por lo que significan, lo que significaron: son el alma viva de los Montes de Oca, el recuerdo de lo que fueron ellos, que se creían los dueños del país, y solamente entrar en esa biblioteca me resulta desagradable, es un lugar que me rechaza y que yo rechazo..." (35-36).

En contraste con la inmensa biblioteca de los Montes de Oca - cautivadora para el bibliófilo y opresiva para Amalia- Conde recuerda el vecindario de su juventud en el que las bibliotecas particulares formadas por libros que se juntaban al azar no llegaban a sumar más de veinte ejemplares. Y aun así, incluso una versión de Huckleberry Finn resumida en Selecciones de Reader's Digest estimula la inteligencia de Conde y la pasión por los libros que será nutrida por su mentor, Cristóbal el Cojo, en la biblioteca del preuniversitario de La Víbora. Esta colección, que Cristóbal hace circular de manera generosa entre los estudiantes, deja en Conde la idea de que los libros son una propiedad común que debe ser dise- 
minada entre el público general. $\mathrm{Y}$, sin embargo, sabemos que desde sus primeros años como "depredador de bibliotecas" Conde, por principio, se ha negado a comprar o vender cualquier libro que tenga el sello de una biblioteca que indique que se trata de un "objeto público" (166). Pero Cristóbal el Cojo también le enseñó que las denominaciones oficiales no siempre sirven para garantizar el acceso de los ciudadanos y que el hecho de coleccionar libros, sea para una biblioteca pública o privada, implica la responsabilidad benjaminiana de transmisión del legado. Cuando está preparando su retiro, Cristóbal anima a los estudiantes a robarse los libros, porque le preocupa que sus sucesores no le den el valor que se merece a la colección que él se ha encargado de juntar: "Llévatelos, sálvalos, pero cuídalos" (167).

Es significativa la ubicación de la enorme biblioteca de La neblina del ayer en El Vedado. Aunque se trata del vecindario en el que vivía la clase media alta de La Habana prerrevolucionaria, el Vedado es también el centro de la vida intelectual de la ciudad, el lugar en el que se encuentra la Universidad de La Habana (fundada en 1728) y también una gran cantidad de instituciones culturales de la revolución. Como promotora de un asesinato que, como en todas las novelas policiales de Padura, termina siendo secundario frente a las reflexiones del policía retirado sobre libros, arte y las conexiones entre el presente cubano y el pasado prerrevolucionario, la biblioteca de El Vedado - junto con la biblioteca del solar en Las palabras perdidas y la biblioteca de la guarida en Fresa y chocolate - genera un desplazamiento de lo que queda de los ideales revolucionarios que proponían el libre acceso a la vida cultural como complemento de la igualdad social. La significativa presencia de la biblioteca en los productos culturales de la Cuba post-soviética sugiere una persistente ambigüedad con respecto a los ideales que fueron artículos de fe para la revolución y que en el presente se niegan a desaparecer, cuando los escritores imaginan el futuro, a pesar de que la crisis económica del Período Especial los haga parecer como frustrados y aparentemente desvinculados de la realidad.

\section{Obras citadas}

Arango, Arturo. La Habana elegante. La Habana: Unión, 1995.

Bejel, Emilio. Gay Cuban Nation. Chicago: University of Chicago Press, 2001.

Benjamin, Walter. Iluminations. New York: Shocken Books, 1969.

Borges, Jorge Luis. Ficciones. Buenos Aires: Emecé: 1956.

-. "La biblioteca de Babel". Sur 1939: 13-16.

Buckwalter-Arias, James. Cuba and the New Origenismo.

Woodbridge, UK: Tamesis, 2010. 
Carpentier, Alejo. El siglo de las luces. Barcelona: Seix Barral, 1964 .

Carranza, Araceli y Xonia Jiménez López. "Biblioteca Nacional

de Cuba". Boletín de la ANABAD 1992: 117-32.

Castillo, Debra. The Translated World: A Postmodern Tour of Libraries

in Literature. Tallahassee: Florida State University Press, 1985.

Castro, Fidel. Palabras a los intelectuales. La Habana:

Ediciones del Consejo Nacional de Cultura, 1961.

Certeau, Michel de. The Practice of Evereday Life. Berkeley:

University of California Press, 1988.

Diccionario de la Literatura Cubana. Vol. ı. La Habana: Letras Cubanas, 1980.

Díaz, Jesús. Las palabras perdidas. Barcelona: Letras Cubanas, 1980.

Eco, Umberto. The Name of the Rose. San Diego: Harcourt Brace Jovanovich, 1984.

-. Postscript to the Name for the Rose. San Diego: Harcourt Brace Jovanovich, 1984.

Escobar, Sarah. "El Sistema de bibliotecas públicas cubanas. Un

proyecto en constante desarrollo". Biblioteca digital. Biblioteca

Nacional de Cuba José Martí. N. P. 12 de octubre de 2012.

Fagen, Richard R. The Transformation of Political Culture in

Cuba. Stanford: Stanford University Press, 1969.

Fornet, Jorge. "La narrativa cubana entre la utopia y el desencanto".

La Gaceta de Cuba 5 septiembre-octubre 2001: 38-45.

-. Los nuevos paradigmas: Prólogo narrativo al siglo

XXI. La Habana: Letras Cubanas, 2007.

Foucault, Michel. Language, Counter-Memory, Practice: Selected Essays and

Interviews. Ed. Donald F. Bouchard. Ithaca: Cornell University Press, 1977.

Fresa y Chocolate. Dir. Tomás Gutiérrez Alea y Juan Carlos Tabío. ICAIC, 1994.

Hamilton, Stuart. "Librarians or Dissidents: Critics and Supporters of the

Independent Libraries in Cuba Project". Progressive Librarian Spring 2002: 3-46.

Highmore, Ben. Everyday Life and Cultural Theory: An

Introduction. London: Routledge, 2002.

Kapcia, Antoni y Par Kumaraswami. "The Feria del Libro and the

Ritualization of Cultural Belonging in Havana". Cultures of the City:

Mediating Identities in Urban Latin/o America. Richard Young y Amanda

Holmes, eds. Pittsburgh: University of Pittsburgh Press, 2010.

Loynaz, Dulce María. Fardín; novela lírica. Madrid: Aguilar, 1951.

Lista de espera. Dir. Juan Carlos Tabio. ICAIC, 2000.

Madagascar. Dir. Fernando Pérez. ICAIC, 1994.

Mateo Palmer, Margarita. "Signs after the Last Shipwreck". Boundary 2 2002: 149-157.

Mayol, Josefina y Jerrold Orne. "Cuban Libraries". Library Quarterly April 1952: 92-124. 
Medin, Tzvi. Cuba: The Shaping of Revolutionary Consciousness.

Boulder: L. Rienner Publishers, 1990.

Memorias del subdesarrollo. Dir. Tomás Gutiérrez Alea. ICAIC, 1968.

Padura, Leonardo. Máscaras. Barcelona: Tusquets: 1997.

-. La cola de la serpiente. La Habana: Unión, 2001.

-. La niebla del ayer. Barcelona: Tusquets, 2005.

-. Adiós Hemingway. Barcelona: Tusquets, 2006.

Paz, Senel. El lobo, el bosque y el hombre nuevo. México: Era, 1991.

Piñera, Virgilio. Electra Garrigó. Teatro Completo. La Habana: Letras Cubanas, 2002.

Quiroga, José. Cuban Palimpsests. Minneapolis: University of Minnesota Press, 2005.

-. Tropics of Desire. Interventions from Queer Latino America.

New York: New York University Press, 2000.

Radford, Gary P. "Positivism, Foucault, and the Fantasia of the

Library: Conceptions of Knowledge and the Modern Library

Experience". Library Quarterly 62. 4 Octubre 1992: 408-424.

Robió, Carlos. "La Biblioteca Nacional, Culture and Politics".

Changing Cuba/Changing World. Nueva York: Bildner Center

for Western Hemispheric Studies, 2008. 41-82.

Rojas, Rafael. El estante vacío: Literatura y política en

Cuba. Barcelona: Anagrama, 2009.

Tabío, Juan Carlos (Dir.). La lista de espera. 2000.

Unruh, Vicky. "All in a Day's Work: Ruins Dwellers in Havana".

Telling Ruins in Latin America. Michael J. Lazzara y Vicky Unruh

(Ed.). Nueva York: Pelgrave Macmillan, 2009. 197-209.

Utopía. Dir. Arturo Infante. Guagua \& Co., 2005.

Whitfield, Esther Katheryn. Cuban Currency: The Dollar and Special

Period Fiction. Minneapolis: University of Minnesota Press, 2008. 